\title{
PENGARUH MANAJEMEN SARANA PRASARANA PEMBELAJARAN DAN IKLIM SEKOLAH TERHADAP MUTU PENDIDIKAN SEKOLAH DASAR DI KECAMATAN BALONGAN KABUPATEN INDRAMAYU
}

\author{
Nurhayati \\ SD Sudimampir Lor 1 Indramayu, nurhayati123@gmail.com
}

\begin{abstract}
ABSTRAK
Penelitian ini fokus pada besar pengaruh manajemen sarana prasarana pembelajaran dan iklim sekolah terhadap mutu pendidikan pada SD Negeri di Kecamatan Balongan Kabupaten Indramayu. Penelitian ini menggunakan metode survai penjelasan (explanatory survey method), yang berusaha menggambarkan dan menginterpretasikan obyek sesuai dengan apa adanya. Hasil penelitian menunjukkan bahwa: (1) Terdapat pengaruh yang positif dan signifikan manajemen sarana prasarana pembelajaran terhadap mutu pendidikan (2) Terdapat pengaruh yang positif dan signifikan iklim sekolah terhadap mutu pendidikan (3) Terdapat pengaruh yang positif dan signifikan manajemen sarana prasarana pembelajaran dan iklim sekolah secara simultan terhadap mutu pendidikan. Selanjutnya, penulis menyarankan agar informasi tentang mutu pendidikan pada SD Negeri di Kecamatan Balongan Kabupaten Indramayu menjadi masukan yang penting. Untuk itu dalam rangka meningkatkan mutu pendidikan pada SD Negeri di Kecamatan Balongan Kabupaten Indramayu guru-guru perlu lebih serius didalam memelihara sarana prasarana pembelajaran dan suasana kenyamanan di sekolah agar dapat mendorong terwujudnya efektivitas proses pembelajaran lebih optimal. Mutu pendidikan pada SD Negeri di Kecamatan Balongan Kabupaten Indramayu sudah sangat baik, namun demikian masih perlu ditingkatkan agar diperoleh kualitas pendidikan secara keseluruhan. Peningkatan kualitas pendidikan antara lain dapat dilakukan dengan cara mengembangkan kesadaran kepada warga sekolah untuk sama-sama mengoptimalkan pemeliharaan dan pemanfaatan sarana prasarana pembelajaran dan kenyamanan situasional sekolah sehingga operasional sekolah berlangsung bagus dari input, proses hingga output.
\end{abstract}

Kata kunci: Manajemen Sarana Pembelajaran, Iklim Sekolah, Mutu Pendidikan

\begin{abstract}
This study focuses on the influence of management of learning infrastructure and school climate on the quality of education in public elementary schools in Balongan District, Indramayu Regency. This study uses an explanatory survey method, which seeks to describe and interpret objects according to what they are. The results of the study show that: (1) There is a positive and significant influence on the management of learning infrastructure for education quality (2) There is a positive and significant influence on the school climate on the quality of education (3) There is a positive and significant effect on the management of learning infrastructure and climate schools simultaneously towards the quality of education. Furthermore, the authors suggest that information about the quality of education in public elementary schools in Balongan District, Indramayu Regency be an important input. For this reason, in order to improve the quality of education in public elementary schools in Balongan sub-district, Indramayu district, teachers need to be more serious in maintaining learning infrastructure and a comfortable atmosphere in schools so as to encourage the realization of more effective learning processes. The quality of education in public elementary schools in Balongan District, Indramayu Regency is very good, however, it still needs to be improved in order to obtain overall quality of education. Improving the quality of education can be done, among others, by developing awareness among school people to jointly optimize the maintenance and use of learning infrastructure and the convenience of school situational facilities so that school operations run well from input, process to output.
\end{abstract}

Key Words: Management of Learning Facilities, School Climate, Education Quality 


\section{PENDAHULUAN}

Jika sebelumnya manajemen pendidikan merupakan wewenang pusat dengan paradigma top-down atau sentralistik, dengan berlakunya undangundang tersebut kewenangan bergeser pada pemerintah daerah, kota, dan kabupaten dengan paradigma bottom-up atau desentralistik dalam wujud pemberdayaan sekolah (Mulyasa,2005:3). ...pemimpin-pemimpin yang menampilkan budaya adalah muliamoral-spiritual yang mantap, semangat bekerja dan berusaha yang ulet yang dilandasi pendayagunaan ilmu pengetahuan, teknologi dan seni tepat guna sejalan dengan etika profesi dalam berbagai bidang, dan kreatif terpujiyang menyenangkan dan menyejukkan setiap insan sehingga menjadi kepercayaan, panutan, dan teladan... (Engkoswara, 2002)

Sarana pendidikan adalah "peralatan dan perlengkapan yang secara langsung dipergunakan dan menunjang proses pendidikan, khususnya proses belajar mengajar, seperti gedung, ruang kelas meja kursi, serta alat-alat dan media pengajaran.” (Mulyasa, 2005),

Sarana adalah segala jenis peralatan, perlengkapan kerja dan fasilitas yang berfungsi sebagai alat utama/pembantu dalam pelaksanaan pekerjaan, dan juga dalam rangka kepentingan yang sedang berhubungan dengan organisasi kerja. (Moenir, 1998)

Prasarana pendidikan dapat diartikan sebagai perangkat yang menunjang keberlangsungan sebuah proses pendidikan, sedangkan definisi prasarana adalah semua perangkat kelengkapan dasar yang secara tidak langsung menunjang pelaksanaan proses pendidikan di sekolah. (Ibrahim Bafadal, 2003)

Prasarana pendidikan dapat diartikan sebagai perangkat penunjang utama suatu proses atau usaha pendidikan agar tujuan pendidikan dapat tercapai. (Riduwan, 2003)

Adapun proses manajemen sarana prasarana meliputi : a) Perencanaan, yaitu kegiatan penyusunan daftar sarana dan prasarana yang dibutuhkan sekolah. b) Pengadaan, yaitu kegiatan menghadirkan sarana dan prasarana untuk menunjang proses belajar mengajar. c) Penyimpanan, pendistribusian, pengunaan, dan penataan sarana dan prasarana pendidikan yang efektif dan efisien. d) Penataan pemeliharaan dan pengawasan, pemeliharaan merupakan pencegahan kerusakan suatu barang sedangkan pengawasan merupakan kegiatan pengamatan, pemeriksaan, dan penilaian 
terhadap pelaksanaan administrasi sarana dan prasarana sekolah. e) Inventarisasi dan pelaporan, inventarisasi merupakan kegiatan melaksanakan pengurusan, penyelenggaraan, pengaturan, dan pencatatan barang-barang. f) Penghapusan, yaitu kegiaan meniadakan barang-barang milik Negara/ daerah dari daftar inventaris karena barang tersebut sudah tidak mempunyai nilai guna. g) Pengawasan dan pertanggungjawaban, yaitu kegiatan mengawasi pemakaian barang-barang milik sekolah dan membuat laporan pertanggungjawaban. (Heryati dan Muhsin, 2014)

Iklim organisasi adalah "lingkungan manusia dimana karyawan bekerja." ( Davis, 2000)

"iklim organisasi sebagai lingkungan internal atau budaya lingkungan pergaulan dari organisasi yang dirasakan anggotanya." (Gannon, 2000)

Iklim organisasi adalah "persepsi individu tentang berbagai aspek yang ada dalam lingkungan organisasi." (Owens, 2002)

Iklim organisasi adalah sejumlah sikap pekerja dalam suatu perusahaan khususnya mengacu pada kesehatan dan kenyamanan kerja. (Sikula, 2000)

Iklim organisasi merujuk pada persepsi terhadap lingkungan sekolah secara umum yang dipengaruhi oleh organisasi formal, organisasi informal, kepribadian anggota. dan kepemimpinan dalam organisasi. (Hoy dan Miskel, 2001)

Terdapat sepuluh dimensi yang perlu diperhatikan dalam melihat iklim organisasi, yaitu: struktur tugas, hubungan imbalan-hukuman, sentralisasi keputusan, tekanan pada prestasi. tekanan pada pelatihan dan pengembangan, keamanan versus risiko, keterbukaan versus ketertutupan. status dan semangat, pengakuan dan umpan balik, serta kompetensi dan fleksibilitas organisasi secara umum. (Steer, 2003)

Iklim partisipatif memiliki ciri antara lain : kepercayaan pada bawahan (trust in subordinates), komunikasi yang terbuka (openness in communication), perhatian dan dukungan pimpinan (considerate and supportive leadership), pemecahan masalah kelompok (group problem solving), otonomi pekerja (worker autonomy), pembagian informasi (information sharing), dan penetapan tingginya hasil sasaran (establishment of high output goals). (Mondy, 2001)

\section{METODE PENELITIAN}

Penelitian ini menggunakan pendekatan kuantitatif, dengan teknik korelasional dan regresi. Populasi penelitian ini adalah guru sekolah dasar negeri di Kecamatan Balongan 
Kabupaten Indramayu yang berstatus Pegawai Negeri Sipil (PNS) yang berjumlah 128 orang. Untuk menentukan jumlah sampel menggunakan rumus Slovin dengan hasil56 responden.

\section{HASIL DAN PEMBAHASAN}

Untuk mengetahui besarnya pengaruh manajemen sarana prasarana pembelajaran (X1) secara individual (parsial) terhadap mutu pendidikan (Y) dapat dilihat dari nilai $\mathrm{t}$ pada tabel Coefficients dibawah ini dengan kriteria pengujian jika tingkat signifikansi lebih kecil dari 0,05, maka hipotesis diterima. Adapun hasil pengujian hipotesis tersebut adalah sebagai berikut tercantum pada tabel 1.

Tabel 1

\section{Uji Hipotesis (t) Variabel $\mathrm{X}_{1}$ terhadap $\mathrm{Y}$}

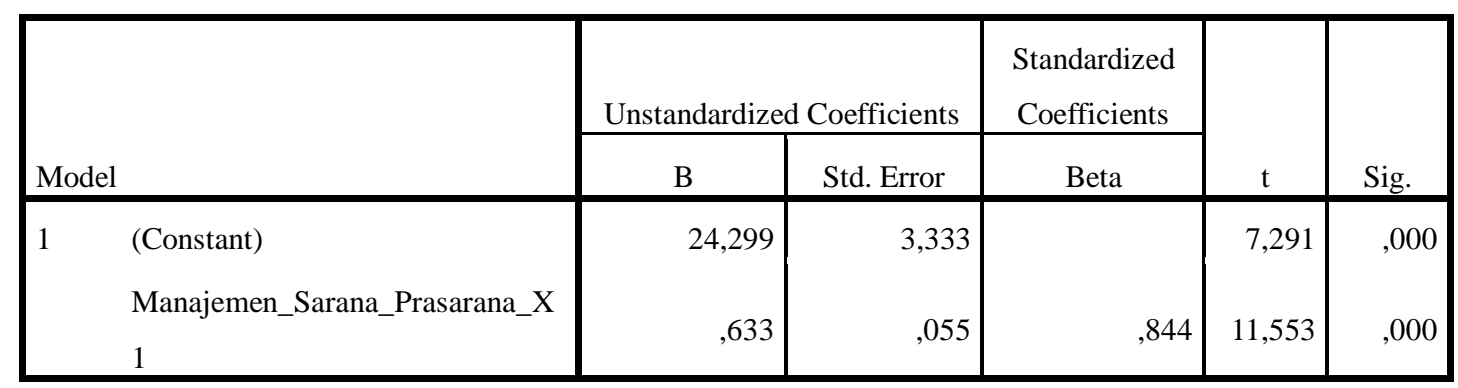

Berdasarkan tabel hasil uji t diperoleh bahwa nilai thitung variabel manajemen sarana prasarana pembelajaran (X1) memiliki nilai sebesar p-value $0,000<$ 0,05 artinya berdistribusi signifikan. Hal tersebut berarti manajemen sarana prasarana pembelajaran (X1) secara parsial berpengaruh terhadap mutu pendidikan (Y). Hal tersebut berarti menerima hipotesis yang menyatakan: “Terdapat pengaruh positif dan signifikan manajemen sarana prasarana pembelajaran terhadap mutu pendidikan pada SD Negeri di Kecamatan Balongan
Kabupaten Indramayu." Persamaan regresi $\mathrm{y}=\mathrm{a} \mathrm{bx} 1$ dari hasil perhitungan diperoleh $\quad \mathrm{y}=24,299+0,633 \times 1$. Konstanta sebesar 24,299 menyatakan bahwa jika ada kenaikan nilai dari variabel manajemen sarana prasarana pembelajaran (X1), maka mutu pendidikan (Y) adalah 24,299. Koefesien regresi sebesar 0,299 menyatakan bahwa setiap perubahan satu skor atau nilai manajemen sarana prasarana pembelajaran akan memberikan skor 0,299 . 
Untuk mengetahui besaran pengaruh iklim sekolah (X2) secara individual (parsial) terhadap mutu pendidikan (Y) dapat dilihat dari nilai $\mathrm{t}$ pada tabel Coefficients dibawah ini dengan kriteria pengujian jika tingkat signifikansi lebih kecil dari 0,05, maka hipotesis diterima. Adapun hasil pengujian hipotesis tersebut adalah sebagai berikut tercantum pada table 2.

Tabel 2

Uji Hipotesis (t) Variabel $\mathrm{X}_{2}$ terhadap $\mathrm{Y}$

\begin{tabular}{|c|c|c|c|c|c|}
\hline \multirow[b]{2}{*}{ Model } & \multicolumn{2}{|c|}{ Unstandardized Coefficients } & \multirow{2}{*}{$\begin{array}{c}\text { Standardized } \\
\text { Coefficients } \\
\text { Beta }\end{array}$} & \multirow[b]{2}{*}{$\mathrm{T}$} & \multirow[b]{2}{*}{ Sig. } \\
\hline & B & Std. Error & & & \\
\hline $1 \quad$ (Constant) & 2,770 & 3,474 & &, 797 & ,429 \\
\hline Iklim_Sekolah_X2 & ,972 &, 056 & ,920 & 17,248 & 000 \\
\hline
\end{tabular}

Berdasarkan tabel hasil uji t diperoleh bahwa nilai thitung variabel iklim sekolah (X2) memiliki nilai sebesar pvalue $0,000<0,05$ artinya signifikan. Dengan demikian iklim sekolah (X2) secara parsial berpengaruh terhadap mutu pendidikan (Y). Hal tersebut mengandung makna diterimanya hipotesis yang menyatakan: "Terdapat pengaruh positif dan signifikan iklim sekolah terhadap mutu pendidikan pada SD Negeri di Kecamatan Balongan Kabupaten Indramayu." Persamaan regresi $\mathrm{y}=\mathrm{a}$ bx 2 dari hasil perhitungan diperoleh $\quad \mathrm{y}=2,770+0,972 \times 2$. Konstanta sebesar 2,770 menyatakan bahwa jika ada kenaikan nilai dari variabel iklim sekolah (X2), mutu pendidikan (Y) adalah 2,770. Koefesien regresi sebesar 0,972 menyatakan bahwa setiap perubahan satu skor atau iklim sekolah akan memberikan skor 0,972.

Untuk mengetahui besarnya pengaruh manajemen sarana prasarana pembelajaran (X1) dan iklim sekolah secara bersama-sama (ganda) terhadap mutu pendidikan (Y) dapat dilihat dari nilai t pada tabel Coefficients dibawah ini dengan kriteria pengujian jika tingkat signifikansi lebih kecil dari 0,05, maka hipotesis diterima. Adapun hasil pengujian hipotesis tersebut adalah sebagai berikut terantum pada table 3 . 
Tabel 3

Uji Hipotesis (t) Variabel $X_{1}$ dan $X_{2}$ terhadap $Y$

\begin{tabular}{|c|c|c|c|c|c|c|}
\hline \multirow{2}{*}{\multicolumn{2}{|c|}{ Model }} & \multicolumn{2}{|c|}{$\begin{array}{c}\text { Unstandardized } \\
\text { Coefficients } \\
\end{array}$} & \multirow{2}{*}{$\begin{array}{c}\text { Standardized } \\
\text { Coefficients } \\
\text { Beta } \\
\end{array}$} & \multirow[b]{2}{*}{$\mathrm{t}$} & \multirow[b]{2}{*}{ Sig. } \\
\hline & & $\mathrm{B}$ & Std. Error & & & \\
\hline \multirow[t]{3}{*}{1} & (Constant) & 4,720 & 3,643 & & 1,295 & ,201 \\
\hline & $\begin{array}{l}\text { Manajemen_Sarana_Prasarana_X } \\
1\end{array}$ & ,128 &, 081 &, 170 & 1,578 & ,121 \\
\hline & Iklim_Sekolah_X2 &, 815 &, 114 & ,771 & 7,144 & 000 \\
\hline
\end{tabular}

Berdasarkan tabel hasil uji t diperoleh bahwa nilai thitung variabel manajemen sarana prasarana pembelajaran $(\mathrm{X} 1)$ dan iklim sekolah (X2) secara bersama-sama (simultan) memiliki nilai sebesar p-value $0,000<0,05$ artinya signifikan. Dengan demikian manajemen sarana prasarana pembelajaran (X1) dan iklim sekolah (X2) secara bersama-sama (simultan) berpengaruh terhadap mutu pendidikan (Y). Hal tersebut membuktikan diterimanya hipotesis yang menyatakan: “Terdapat pengaruh positif dan signifikan manajemen sarana prasarana pembelajaran dan iklim sekolah secara bersama-sama (simultan) terhadap mutu pendidikan pada SD Negeri di Kecamatan Balongan Kabupaten Indramayu".

Untuk mengetahui persamaan regresi dapat dilihat dari tabel di atas. Berdasarkan tabel tersebut menunjukkan persamaan regresi linier ganda :

$\hat{\mathrm{Y}}=4,720+0,128 \mathrm{X} 1+0,815 \mathrm{X} 2$
Persamaan tersebut menyatakan bahwa setiap penambahan X1 dan X2 sebesar 1 maka akan meningkatkan $Y$ sebesar 0,128 dan 0,815 , artinya setiap peningkatan manajemen sarana prasarana pembelajaran dan iklim sekolah sebesar 1, akan meningkatkan mutu pendidikan sebesar 0,128 dan 0,815 .

Pembahasan secara keseluruhan dari tiga variabel terebut adalah pertama, bahwa permasalahan yang ingin dijawab dalam penelitian ini adalah adakah pengaruh manajemen sarana prasarana pembelajaran terhadap mutu pendidikan pada SD Negeri di Kecamatan Balongan Kabupaten Indramayu. Secara empirik, hasil penelitian ini menginformasikan: (1) terdapat pengaruh signifikan antara manajemen sarana prasarana pembelajaran terhadap mutu pendidikan pada SD Negeri di Kecamatan Balongan Kabupaten Indramayu, serta (2) besarnya pengaruh manajemen sarana prasarana pembelajaran terhadap mutu pendidikan 
pada SD Negeri di Kecamatan Balongan

Kabupaten Indramayu ditunjukkan oleh hasil penelitian bahwa manajemen sarana prasarana pembelajaran yang terdiri dari dimensi: (1) Perencanaan; (2) Pengadaan; (3) Penyimpanan; (4) Pemeliharaan; (5) Penghapusan; (6) Pengawasan (Heryati dan Muhsin, 2014:224), membawa implikasi terhadap mutu pendidikan yang meliputi dimensi: (1) Kelembagaan; (2) Proses pembelajaran; (3) Kualitas produk (Fattah, 2012). Namun demikian mutu pendidikan pada SD Negeri di Kecamatan Balongan Kabupaten Indramayu ini tidak hanya dipengaruhi oleh manajemen sarana prasarana pembelajaran saja, ada faktor lain (epsilon), selain iklim sekolah, yang juga berpengaruh, yang tidak dikaji dalam penelitian ini.

Dengan demikian, hasil penelitian ini mengindikasikan bahwa semakin tinggi tingkat kondisi bagusnya manajemen sarana prasarana pembelajaran guru pada pada SD Negeri di Kecamatan Balongan Kabupaten Indramayu, maka akan diikuti oleh semakin tingginya tingkat mutu pendidikan pada SD Negeri di Kecamatan Balongan Kabupaten Indramayu tersebut.

Berdasarkan temuan empirik yang menunjukkan adanya pengaruh signifikan antara manajemen sarana prasarana pembelajaran terhadap mutu pendidikan, maka hasil penelitian ini memberikan beberapa informasi, di antaranya: (1) tingkat manajemen sarana prasarana pembelajaran yang diterima oleh guru pada SD Negeri di Kecamatan Balongan Kabupaten Indramayu memberikan pengaruh yang berarti terhadap mutu pendidikan pada SD Negeri di Kecamatan Balongan Kabupaten Indramayu tersebut, (2) salah satu cara untuk meningkatkan mutu pendidikan pada SD Negeri di Kecamatan Balongan Kabupaten Indramayu adalah dengan meningkatkan perhatian pada manajemen sarana prasarana pembelajaran guru, serta (3) kontribusi yang diberikan oleh pengaruh manajemen sarana prasarana pembelajaran terhadap mutu pendidikan adalah sebesar $71,2 \%$, sementara sisanya dipengaruhi oleh variabel lain, selain variabel iklim sekolah, yang tidak dikaji dalam penelitian ini (epsilon).

Kedua, permasalahan yang ingin dijawab dalam penelitian ini adalah adakah pengaruh iklim sekolah terhadap mutu pendidikan pada SD Negeri di Kecamatan Balongan Kabupaten Indramayu. Secara empirik, hasil penelitian ini menginformasikan: (1) terdapat pengaruh yang signifikan antara iklim sekolah terhadap mutu pendidikan pada SD Negeri di Kecamatan Balongan 
Kabupaten Indramayu, serta (2) besarnya pengaruh iklim sekolah terhadap mutu pendidikan pada SD Negeri di Kecamatan Balongan Kabupaten Indramayu ditunjukkan oleh hasil penelitian bahwa iklim sekolah yang terdiri dari dimensi: (1) Perilaku dinamis kepala sekolah, (2) Semangat kerja, (3) Kejelasan tugas pokok dan fungsi, (4) Keakraban (Hoy dan Miskel, 2001:223224), membawa implikasi signifikan terhadap mutu pendidikan yang meliputi dimensi (1) Kelembagaan; (2) Proses pembelajaran; (3) Kualitas produk (Fattah, 2012). Namun demikian mutu pendidikan pada SD Negeri di Kecamatan Balongan Kabupaten Indramayu ini tidak hanya dipengaruhi oleh iklim sekolah saja, ada faktor lain (epsilon), selain manajemen sarana prasarana pembelajaran, yang juga berpengaruh, yang tidak dikaji dalam penelitian ini.

Dengan demikian, hasil penelitian ini mengindikasikan bahwa semakin bagus iklim sekolah pada SD Negeri di Kecamatan Balongan Kabupaten Indramayu, maka akan diikuti oleh semakin tingginya tingkat mutu pendidikan pada SD Negeri di Kecamatan Balongan Kabupaten Indramayu tersebut.
Berdasarkan temuan empirik yang menunjukkan adanya pengaruh yang signifikan antara iklim sekolah dengan mutu pendidikan, maka hasil penelitian ini memberikan beberapa informasi, di antaranya: (1) tingkat iklim sekolah pada SD Negeri di Kecamatan Balongan Kabupaten Indramayu memberikan pengaruh yang berarti terhadap mutu pendidikan pada SD Negeri di Kecamatan Balongan Kabupaten Indramayu tersebut, (2) salah satu cara untuk meningkatkan mutu pendidikan pada SD Negeri di Kecamatan Balongan Kabupaten Indramayu adalah dengan mengembangkan iklim sekolah, serta (3) kontribusi yang diberikan oleh pengaruh iklim sekolah terhadap mutu pendidikan adalah sebesar $84,6 \%$, sementara sisanya dipengaruhi oleh variabel lain, selain variabel manajemen sarana prasarana pembelajaran, yang tidak dikaji dalam penelitian ini (epsilon).

Ketiga, permasalahan yang ingin dijawab dalam penelitian ini adalah adakah pengaruh manajemen sarana prasarana pembelajaran dan iklim sekolah secara bersama-sama terhadap mutu pendidikan pada SD Negeri di Kecamatan Balongan Kabupaten Indramayu. Secara empirik, hasil penelitian ini menginformasikan: (1) terdapat pengaruh yang signifikan antara manajemen sarana prasarana 
pembelajaran dan iklim sekolah secara simultan terhadap mutu pendidikan pada SD Negeri di Kecamatan Balongan Kabupaten Indramayu, serta (2) besarnya pengaruh manajemen sarana prasarana pembelajaran dan iklim sekolah secara bersama-sama terhadap mutu pendidikan pada SD Negeri di Kecamatan Balongan Kabupaten Indramayu ditunjukkan oleh hasil penelitian bahwa manajemen sarana prasarana pembelajaran yang terdiri dari dimensi (1) Perilaku dinamis kepala sekolah, (2) Semangat kerja, (3) Kejelasan tugas pokok dan fungsi, (4) Keakraban (Hoy dan Miskel, 2001:223224), serta iklim sekolah yang terdiri dari dimensi: (1) Perilaku dinamis kepala sekolah, (2) Semangat kerja, (3) Kejelasan tugas pokok dan fungsi, (4) Keakraban (Hoy dan Miskel, 2001:223224), membawa implikasi yang signifikan terhadap mutu pendidikan yang meliputi dimensi: (1) kesadaran, (2) penegakkan aturan, (3) keteladanan, (4) kepatuhan, (5) ketertiban, dan (6) pengorbanan. Namun demikian mutu pendidikan pada SD Negeri di Kecamatan Balongan Kabupaten Indramayu ini tidak hanya dipengaruhi oleh manajemen sarana prasarana pembelajaran dan iklim sekolah saja, ada faktor lain (epsilon), yang juga berpengaruh, yang tidak dikaji dalam penelitian ini.

Dengan demikian, hasil penelitian ini mengindikasikan bahwa semakin tinggi tingkat kondisi bagusnya manajemen sarana prasarana pembelajaran dan iklim sekolah pada SD Negeri di Kecamatan Balongan Kabupaten Indramayu, maka akan diikuti oleh semakin tingginya tingkat mutu pendidikan pada SD Negeri di Kecamatan Balongan Kabupaten. Indramayu tersebut.

Berdasarkan temuan empirik yang menunjukkan adanya pengaruh signifikan antara manajemen sarana prasarana pembelajaran dan iklim sekolah terhadap mutu pendidikan, maka hasil penelitian ini memberikan beberapa informasi, di antaranya: (1) tingkat manajemen sarana prasarana pembelajaran dan iklim sekolah yang dirasakan oleh guru pada SD Negeri di Kecamatan Balongan Kabupaten Indramayu memberikan pengaruh yang berarti terhadap mutu pendidikan pada SD Negeri di Kecamatan Balongan Kabupaten Indramayu tersebut, (2) salah satu cara untuk meningkatkan mutu pendidikan pada SD Negeri di Kecamatan Balongan Kabupaten Indramayu adalah dengan memberikan perhatian pada manajemen sarana prasarana pembelajaran guru dan mengembangkan iklim sekolah, serta (3) 
kontribusi yang diberikan oleh manajemen sarana prasarana pembelajaran dan iklim sekolah terhadap mutu pendidikan adalah sebesar $85,3 \%$, sementara sisanya dipengaruhi oleh variabel lain yang tidak dikaji dalam penelitian ini (epsilon).

\section{PENUTUP}

Berdasarkan permasalahan yang telah dirumuskan serta hasil penelitian dan pembahasan, maka dapat dikemukakan beberapa kesimpulan sebagai berikut:

a) Terdapat pengaruh yang positif dan signifikan manajemen sarana dan prasarana pembelajaran terhadap mutu pendidikan pada sekolah dasar di Kecamatan Balongan Kabupaten Indramayu. Besarnya pengaruh manajemen sarana dan prasarana pembelajaran terhadap mutu pendidikan pada sekolah dasar di Kecamatan Balongan Kabupaten Indramayu adalah $71,2 \%$.

b) Terdapat pengaruh yang positif dan signifikan iklim sekolah terhadap mutu pendidikan pada sekolah dasar di Kecamatan Balongan Kabupaten Indramayu. Besarnya pengaruh iklim sekolah terhadap mutu pendidikan pada sekolah dasar di Kecamatan Balongan Kabupaten Indramayu adalah 84,6 \%. c) Terdapat pengaruh yang positif dan signifikan manajemen sarana prasarana pembelajaran dan iklim sekolah secara simultan terhadap mutu pendidikan pada sekolah dasar di Kecamatan Balongan Kabupaten Indramayu. Besarnya pengaruh manajemen sarana prasarana pembelajaran dan iklim sekolah secara simultan terhadap mutu pendidikan pada sekolah dasar di Kecamatan Balongan Kabupaten Indramayu adalah 85,3 \%.

\section{UCAPAN TERIMAKASIH}

Terimkasih kepada semua pihak yang telah membantu penulisan karya ilmiah ini.

\section{DAFTAR PUSTAKA}

Arikunto, Suharsimi (2007). Manajemen Penelitian. Jakarta: Rineka Cipta.

Bafadal, Ibrahim. (2003). Peningkatan Profesionatisme Guru Sekolah Dasar. Jakarta: Sinar Grafika Offset.

Davis, Keith. (2000). Human Behavior at Work: Organizational Behavior. Metro Manila: McGraw-Hiil Publishing Co.I.td.

Engkoswara, (2002), Menuju Indonesia Modern 2020. Bandung: Yayasan Amal Keluarga.

Gannon. Martin J. (2000). Organizational Behavior A Managerial and Organizational Perspective. Boston: Little Brown and Company. 
Hoy, W.K. \& Cecil G.M. (2001).Education Administration: Theory, Research, and Practice. New York: Mc GrawHill.

Moenir, A.S. (1998). Kepemimpinan Kerja Teknik dan Keberhasilannya. Jakarta : Bina Aksara.

Mondy. K. Wayne. Robert E Holmes dau Edwin E Flippo. (2001). Management: Concept and Practice. Boston: Allyn and Bacon.

Mulyasa, E., (2005), Menjadi Guru Profesional, Bandung : PT. Remaja Rosdakarya

Owens, Robert G. (2002). Organizational Behavior in Education. 5th Edition. Boston: Allyn and Bacon.

Riduwan. (2003). Metode dan Teknik Menyusun Tesis. Bandung: Alfabeta.

Sikula, Andrew F. (2000). Personnel Administration and Human Resources Management. Santa Barbara: John Wiley \& Sons, Inc.

Steer. Richard M. (2003). Efektivitas Organisasi. Cetakan kedua. Jakarta: Erlangga. 